\title{
A SOCIOLINGUISTIC APPROACH TO PROFESSIONAL IDENTITY CONSTRUCTION IN TOURISM
}

\author{
SILVIA BLANCA IRIMIEA ${ }^{1}$
}

\begin{abstract}
A Sociolinguistic Approach to Professional Identity Construction in Tourism. Identity is an issue that affects all society and all professions, including tourism professions. The process of professional identity construction and/or reconstruction is not reserved only to the academia and to the specialised training institutions, but has become a complex process laid bare for public debate by the media and engaging Web 2.0 and many other societal institutions and processes. If the process has been widely discussed from the point of view of the professionals' training for different careers (management, communication, marketing, hospitality) or from that of tourist identities (Harrison, 2003; Thurlow \& Jaworsky, 2010) and tourism relationships (Thurlow \& Jaworsky, 2010), professional group identity in tourism has received less research attention from sociolinguists. Thus, it is the purpose of the present study to address some sociolinguistic considerations that have acquired relevance in the identity formation of groups of employees in tourism based on discourse and interactional sociolinguistic aspects. While surveying the early contributions of Goffman (1950s), Sacks (1960s), Schegloff (1987) and the further advancements in the field (Van Dijk, 1993, 1997; Drew and Heritage, 1993, Miller, 1994; Stubbe, 1998; Cicourel, 2003; 2003; Koester, 2004; Richards, 2006), the study is focused on the case of group identity formation in travel agencies. Finally, it seeks to reveal the temporary nature of identities, the lack of concern of travel agencies for the constriction, reconstruction, survival of group identity.
\end{abstract}

Keywords: group identity, tourist identity, professional identity, group identity construction, representation, misrepresentation.

${ }^{1}$ Faculty of Letters, Babeș-Bolyai University of Cluj-Napoca, Romania; Director of the Centre for Tourism Training, s_irimiea@yahoo.com 


\section{Introduction}

Identity is an issue that concerns all members of society, who display both their personal identities and the identities or roles assumed by them or assigned to them by the professional group they belong to. Identity has become the object of public analysis whereby the media, PR specialists and politicians lay bare identities for public consumption. Groups construct political identities to win popular support, to promote corporate identities and to impose control on employees and customers.

The process of identity construction itself has entered a new, more complex level as many factors, one of which is the Web, contribute to its making. Nowadays, the Web offers multiple representations and the possibility of creating many parallel, or coexisting identities, each valid for a specific domain or setting.

The issue of identity construction has a rather short tradition, which acquired prominence and consistency in the 1990s, although the 1950s works of Goffman and Harold Garfinkel in ethnomethodology, those of Harvey Sacks (1960s) in conversation analysis, and Schegloff's (1987) contributions influenced to a great extent the push towards studies in identity creation. Thus, the contributions to the issue of identity construction have come from several traditions, such as interactional sociolinguistics, conversational analysis, ethnographic studies, institutional discourse studies, workplace interactional analyses, and many other disciplines.

Even the process of data collection on these processes was challenged by the questions that surround the representation of self (Atkinson and Silverman, 1997; MacLure, 1993) and all the known and unknown aspects that lie behind it. In 1998 Craib asserted that 'The central feature of the self in modern society is its reflexibility, a constant questioning and reconstruction in a lifetime project' and that 'We are constantly constructing and revising our personal stories and so reconstructing ourselves' (p. 2).

Identity (re)creation like other research areas has acquired a sociolinguistic turn becoming the object of dissection for sociolinguists. Many linguists have attended to discourse structure, interactional discourse, looking for patterns that could be related to 'structures' or 'orders' of society and ideology. According to conversation analysts, the sort of structuring that interactants are subject to in a conversation and reproduce in their talk already represents a core dimension of social structure (Jaworski and Coupland, 2014). Conversational production is linked to the production of social order (idem) and can, thus, through micro-level (linguistic, textual, intertextual) insights explain macro-level (societal, ideological, cultural, etc.) processes, all of which are reflections of identities or group identities. 
The concept of identity in relation to discourse can be variously defined. It can represent a variable accounting for the use of particular linguistic or discourse devices, or a means of referring to and making reference to and inferencing about self and others (Zimmerman, 1998). Identity has been studied within the field of workplace interaction (Stubbe, 1998; Cicourel, 2003; Koester, 2004), by institutional discourse analysts (Drew and Heritage, 1993; Miller, 1994) and interactional sociolinguists.

In tourism, the issue has been approached by sociologists like Thurlow and Jaworsky (2010) who discuss both tourist identities as reshaped by the global community of practice and the prevalent role of language in creating host-tourist identities and interactions. Following Van Dijk's lead (1993, 1997), Hannam and Knox (2015) speak about the construction and display of identities, of social relations and knowledge, and the construction of social and cultural means in the achievement of tourism-specific actions. The association of everyday social and cultural means with the category of 'context' in which actions occur create the premise for an interdisciplinary and transdisciplinary study between tourism, interactional sociolinguistics, and other disciplines. These assertions coupled with the lack of determinacy create the premises for vast and entangled processes that cannot be solved by one research tradition, but call for an interdisciplinary, integrative perspective that could embrace several investigation methods and insights.

Amid these developments and challenges, the present study seeks to tackle such issues as the construction, the reconstruction and the display of identities in professional contexts. The study is focused on a particular, but less investigated environment, that of tourism agencies. At the same time, the study is intended to reveal the advancements made in the field and the interdisciplinary nature of the processes involved in identity construction. The study points to the difficulty of drawing up generalisations regarding the features and conditions of group identity (re)creation in the absence of consistent empirical and corpus studies.

\section{Group identity}

The impenetrability of the processes by which the self is constructed or reconstructed has attracted the interest of many researchers. The investigation of the self and group identity has called Bolinger's attention, who observed that 'there is no limit to the ways in which human beings league themselves together for self-identification, security, gain, amusement, worship, or any other purposes that are held in common' (1975:333). Thus, groups have been formed for some particular reasons, mutually recognised by its 
members. Groups have acquired a distinctive identity based on the reasons that brought them together and were further on nurtured by the established group relationships. However, little is known about these processes and one way to get to them is to study the human interactions that emerge within those groups. (Richards, 2006). Group identity and relationships have become more important for researchers, in particular as such groups have come together for the purpose of achieving common goals, such as professional, societal, etc., thus establishing professional communities with identifiable, common goals and identities.

Gradually, following the progress of society and economy, researchers turned their investigations to the world of business groups and interactions in an attempt to understand the multiple processes and ties that keep individuals together and loyal to their community. Interest has, thus, moved towards the collaborative professional group, towards the importance of mutually supportive teams and the ways in which the cultures that help them flourish and survive could be developed.

To this end, investigations followed the interactional bases that generated the groups and kept them flourishing. Other research threads examined the psychological aspects that kept groups together, for example, 'group psychology', and focused on aspects which could shed light on how groups acted and achieved their common goals, on how they turned successful or how they failed. It has been assumed that such groups have created their own processes based on interactional patterns (including the decision-making ones), some of which have accounted for their success. These decisions, which do not emerge overnight, are the result of talks and interactional practices fostered within the group, which emerge as part of the group's interactional identity, and which should be different from those of other groups. The interactional group identity is developed through many meetings, formal or informal encounters, spontaneous talks or planned ones (Richards, 2006). Some researchers wandered whether these interactional patterns are traceable in the everyday talk of the group, whether they represent a feature of the evolution of all collaborative enterprises, or whether they can be detrimental to the groups isolating them and making them more vulnerable.

\section{(Collaborative) professional group identity}

Identity is formed through action and refers to the construction, the reaffirmation or reconstruction of identities. The processes that are involved are partially reflected in the formal and informal, individual and group talks, in the way members of a group position themselves vis-à-vis one another and 
the outside world. Some of the traces or reflections of these processes are identifiable and revealed both deliberately or accidentally. However, since the semiotic resources that professionals use to state or restate their status are so immensely varied, rich and subtle that our conscious control over them is limited, and so is our capacity to understand them. It is this diversity of forms of expressions and the limitless forms of individual linguistic behavior that make sociolinguistic generalisations less valid and sustainable. In addition, the variety and breadth of professional environments, each with its specific features, to which other sociological factors such as education, and human traits such as trust, confidence, loyalty, etc. may influence to a great extent the sociolinguistic behavior of a member of a specific professional community, increasing or limiting his individual contribution to group identity.

Group identity cannot be static, as it is subject to permanent changes and influences that result from the intercourses that the group has with the outside world as it redefines itself vis-à-vis all the outside influences. Even labels attributed to groups of professionals, such as 'Our ITs' may change over time, as they reflect a particular perspective on the group which captures a major feature or some representative features of that group at a certain moment. The perspective itself may change or may be revised as a consequence of the changes that occur in the 'standard description' or perception, as the dynamic processes of identity construction and as the group redefines itself through its interaction with the outside world.

Thus, the process of identity (re)construction is an ongoing process, but, once a group identity is created, it does not necessarily last. Richards (2006) speaks of successful groups and of groups, which, in spite of their temporary success, eventually, failed. His research was intended to highlight the nature of three successful professional groups and the interactional foundations on which they were built, but which eventually broke up. The research took Richards (idem) well beyond the borders of linguistic study, into group psychology and the reasons that might have called for the inappropriate decisions that contributed to the dissolution of group. Richards asks himself whether the traces of the patterns that may lead to break-ups can be detected in the everyday talks of such groups as well as a feature inherent to the evolution of the groups that might eventually undermine its own existence or constitution.

The Membership Categorisation Analysis once launched by Sacks (1992 a and b) and other followers (Hester and Heglin, 1997; Psathas, 1999; Lepper, 2000) has mapped out a research tradition that shows how the membership of a given category (e.g. 'doctor', 'mother', etc.) is made relevant through the use of Membership Categorisation Devices and related rules. MCA has developed in parallel with other traditions from common ethnomethodological roots. In turn, 
ethnomethodology established itself as a tradition characterised by a diversity of forms and directions with overlapping strands of inquiry, with resemblances and differences. Two such traditions are 'conversation analysis' and MCA, both with their origins in the work of Sacks (1992 a and b), but which have developed independently of each other. While conversation analysis has focused on the sequence of features in interactions, MCA was aimed at the categorisation aspects of social interactions. However, Hester and Heglin suggest that 'both the sequential and the categorization aspects inform each other' (1997, p. 2). They further assume that the particular sequence of items used in an interaction depends on the membership categories of the speakers and conclude that 'social identity provides a sense of the (sequentially organized) talk, just as the talk provides for a sense of social identity' (idem). They also admit that 'in practice these aspects (the sequential and categorisational) are so closely intertwined as to be separable only for the purposes of analysis' $(1997$, p. 3). In this respect, they say that teachers, for example, are recognised as teachers by virtue of the production of particular sorts of sequentially positioned utterances. Membership categories (as described by Sacks) are classifications or social types that may be used to describe persons (idem). The assumption that 'collectivities' can be regarded in the same way as personal membership categories originated in Sacks' work, who also anticipated the development of the concept of 'classes'. Collectivities or 'collectivity (membership) categorisations' range from named institutions to general designations, such as 'systems' (e.g. 'the legal system', 'state bureaucracy', etc.). Hester and Heglin point out that the way in which the use of such categories displays organisational features similar to those in relation to personal membership categories are not to be presumed a priori' and say that they 'are a matter for empirical investigation' (1997, p. 3).

According to Sacks, 'Membership categorization devices' are 'any collection of membership categories, containing at least a category, which may be applied to some population containing at least one member, so as to provide, by the use of some rules of application, for the pairing of at least a population member and a categorisation device member'. In other words, a MCD is both a collection and rules of application.

Sacks provides two rules for applying membership categories. The first of these two rules is the economy rule, which speaks for the adequacy of using a single membership category to describe a member of a population. His does not mean that one member or person cannot be described in terms of several categories, but that in order for a person to be recognised a single category would be sufficient. Thus, for the introduction of a person it would be fair and enough to use one membership category instead of providing more categories. 
For example, a description like 'he's my university colleague' would supply all the necessary information. The second rule of application is the consistency rule and holds that if some population of persons is being categorised [...], then that category or other categories of the same collection may be used to categorise further members of the population' (Sacks, 1974 a, p. 219).

Sacks also speaks about the concept of 'boundedness', which is another hallmark of his conceptual framework, by which he means activities that are carried out by members of particular categories.

The attention given to the interaction of professional groups has stimulated further research and developments in the field. Drew and Heritage (1993) explored the relationship between ordinary conversations and institutional interaction and pointed out the ways in which institutional realities are made relevant and are traceable in interactions. In their 1993 work Drew and Heritage highlight the goal orientations, the specific and particular constraints on allowable inferential frameworks, while, in a later book, Drew and Sorjonen (1997) focus on orientation to institutional identities through person reference, lexical choice, grammar forms, turn-taking and institutionally specific inferences. Drew (2003) notes that in spite of the fact that each speaker, whether client or institutional representative, designs his /her own language in order to achieve particular institutional or professional goals, much of the institutional reality is made evident in the talk. The particularities of talk design vary from institution to institution and from encounter to encounter 'but there is clear evidence that particular linguistic phenomena can be traced through their use in a range of different institutional settings' (Richards, 2006, p. 8).

Beyond the ways in which institutional speaking is made relevant through talk, Arminen (2002) draws attention to the fact that institutional realities are made relevant 'in the way in which the constitution of the talk reveals the institutional resources that are used to perform relevant tasks' (Richards, 2006:8). This leads to the assumption that institutional interaction does not reveal only the peculiarities of some given situations, but that it also captures the wider context of institutional norms and practices. Miller renders this broader significance of institutional discourse and its features. First, he notes that institutional discourses consist of the fundamental assumptions, concerns, and vocabularies of members of settings and their usual ways of interacting with one another', then he argues that institutional discourses are 'standardised frameworks for anticipating, acting in, and reflecting on social settings and interactions' and, finally, he admits that 'They allow and constrain setting members to organise their interactions as instances of standardized types of social relationships and produce conditions for responding to issues in predictable ways' (1994, p. 282-3). 
A greater emphasis was placed on the reflexive relationship between local activities and workplace discourses (Cicourel, 2003) where the subtleties of the interplay between social and institutional activity were captured. Similarly, Koester's (2004) investigations into the relationship between relational and transactional exchanges provide insights into the use of relational sequences. Further studies shed light on everyday workplace interactions (Stubbe, 1998) insisting on exchanges that are part of institutional life but do not stand for formal business encounters.

Gradually, these studies have shown that participants in interactions draw on a wide range of interactional resources and, in spite of the fact that the interactional resources are rather familiar and common, the ways in which they are used are personal and surprising (Richards, 2006).

An interesting approach that is helpful in the analysis of group interaction is Goffman's distinction between front and back stage activities. Goffman proposes the concept of a region, which is 'any place that is bounded to some degree by barriers of perception' and makes a clear distinction between a front region (where the professional performance takes place) and a back region (where all considerations applying in the front are suspended). Goffman goes further suggesting that in western society there are two corresponding behavioural languages associated with the two settings and describes them in the following words: 'The backstage language consists of reciprocal firstnaming, cooperative decision-making, profanity, open sexual remarks, elaborate gripping, smoking, informal dress, "sloppy" sitting and standing posture, use of dialect or sub-standard speech, etc.' (1959/1971, p. 129). In regard to front stage behavior language, he takes it to be 'the absence' or the 'opposite' of all the mentioned features. Richards (2006) suggests that in large organisations the front office is a locus for the interaction between clients and employees, while the back regions stand for the separation of insiders from outsiders (clients). This is also the place where complex interactional behaviours come into play. Critics of the approach recognise that such a characterisation is needed but suggest that the complexities of reality call for a characterisation that could respond to them. A new characterisation should differentiate between front and back stage and front and back region, where the former should stand for physical settings and the latter for specific behavioural constructions within these settings (Richards, 2006). Sarangi and Roberts (1999) use Goffman's distinction between front and back region activities, but develop their own approach in terms of front and back stage. They distinguish frontstage studies, focused on insider/outsider encounters, from backstage studies where the emphasis is laid on how the institutional world and professional knowledge are constructed. They also suggest that these differences may account 
for the ways in which the professional world is created backstage and represented frontstage (Richards, 2006). In his 2006 book, Richards draws on these assumptions and demonstrates how participants use 'representations of frontstage realities as a resource in their construction of collaborative identity' (p. 11).

One further remark regarding the construction of identities is that the process depends on a variety of local practices and on the history behind it (Richards, 2006). In this respect, Richards (2006, p. 12) admits that 'Nothing happens of itself; somewhere there is a history, somehow there are consequences'. This leads to another remark, that the analysis of identity construction does not lend itself to generalisations of any kind but may capture the uniqueness of the particular (idem).

\section{Group identity in travel agencies}

Sociolinguistic investigations into tourism and its language were undertaken by many researchers. One of the notable and pioneering books in the sociology of tourism was Graham Dann's seminal book 'The Language of Tourism: A Sociolinguistic Perspective' (Irimiea, 2018). Dann looks at how tourism uses language as means of social control in hotels and resorts (idem). According to Dann, a hotel, for example, can be considered 'as an establishment which encapsulates tourists protecting them from outside dangers' and affirms that 'Through its total institution-like qualities, the hotel above all manages its protégés' (1996:88). Dann quotes Wood's assumption that hotels 'are in essence agents of social control' (Wood, 1994 quoted in Dann, 1996:88), and that 'the larger the hotel the greater the social control exercised by the management' (Wood, 1994 cited in Dann, 1996:88). We can thus assume that in a most general sense, social control is a regulation of human behavior and tourists recognize that there are both implicit obligations to use the services provided by a hotel as well as constraints upon their enjoyment (Irimiea, 2018). Dann's book stimulated and influenced other sociolinguistic investigations into the language of tourism (Thurlow and Jaworsky, 2003; Jaworsky and Pritchard (eds.) 2005; Cappelli, 2006; Fox 2006b; Phipps, 2006; Brice, 2007; Jaworsky, Thurlow, Ylanne-McEwen and Lawson, 2007), which insisted rather on language as 'a creator of identities, power and social differences in the context of tourism' (Fox, 2008: 20).

The language of tourism as the language of social control and its role in the textualization and (re)contextualization of identity and relationship in tourism discourse was discussed by Thurlow and Jaworsky (2003), but the issue of travel agencies as containers of customs, beliefs and values that shape their identity and that must be further on transmitted to the public has not 
been tackled. Nor have the methods that managers, leaders or simply employees employ to reach this end been discussed from the sociological and linguistic point of view.

In tourism the employees' move from one job to another, or from one group to another is more dynamic for the mere reason that many jobs are seasonal. Many jobs in the industry, such as those of travel agent, travel guide, resort manager, etc. depend on seasonal occupational policies and the employees' own preference given to one company or another. In such profession-specific conditions, group identity can hardly flourish in spite of the efforts of managers or loyal employees to keep to a group identity or culture.

More stable groups and group identities can be built in the hotel sector, where groups are carefully built on the basis of well-established recruitment requirements and policies. These groups are thereafter monitored and consolidated by skillful managers or leaders. Such groups, mainly identifiable by the departments they work in, are based on common, understood and accepted goals, on shared practices, values, on mutual trust, confidence and reciprocal satisfaction. Group identity is carefully built around these principles and affordances, most of which make up the 'culture' of the group or company. Strong groups hold to their shared values and practices and make the members proud of their belonging to such groups. This is also something that managers or leaders appreciate most and seek to enhance.

On the other hand, the identities created through a guide-tourist encounter are based on a relationship that lasts for a few hours, days, months or more. They are temporary identities established on the ground of their common, shared settings, topics and the participants' willed adherence to the group as well as their desire to stay as a member of that temporary group. The new group identity is an agreed one established for the period of time of the common experience, where the participants partly give in their own identities to become visitors/tourists animated by the desire to visit places, to enjoy their unique experience and, finally, have fun. This new, shared or collective identity is reflected in the frequent use of pronouns like 'we' (as in 'We shall visit..., We shall see...,) 'our' (as in 'our trip', 'our programme', etc.). The new, collective identity is dropped as soon as the tourists return to their homes, but crops up in their interactions whenever they are reminiscing episodes of their experience, when they refer to the shared tourist identity with words like 'we visited', 'we all enjoyed...', etc.

This example contrasts with the strong, individual and professional identities revealed by the travel agent- tourist (sales) encounters or interactions. In this particular situation, neither participant declines his/her own personal and professional identity for any moment during the conversation. This 
keeping to one's own personal, professional or social affiliation is manifest in the utterances made in which the travel agent adopts his/her professional role/identity and consequently behaves and speaks like one. The social and professional distance created by the two roles does not enhance a shared perspective and the adoption of a temporarily agreed on, common, group identity and relationships.

As a result of the investigation of the views some travel agency workers (from several agencies) have on group identity, many agreed that the professional group identity is reflected within the group through their common goal, common interest which rests on the fulfilment of job responsibilities. Since travel agencies are small firms, their managers do not seek to transmit too much of what might be termed 'group identity' nor nurture the awareness of a common culture. Agents or workers are required to achieve high level communication and sales targets, they are made aware of the common goals, but are less instructed on the mechanics of how group identity is fostered in the firm/agency. Reversibly, raising awareness of group identity is a constant concern for larger, international and consolidated travel agencies which are aware of the role played by representing a trustworthy company and of cultivating its identity both within and outside the company.

If asked what methods do companies or agencies use to form, maintain and consolidate group identity, travel agents agreed that each agency would design or use its own methods. However, they mentioned the following characteristics: enhancing mutual respect, reciprocal assistance and willingness to help colleagues achieve the common goals and the concern to create a pleasant atmosphere. A company strategy that necessarily fosters group identity and company loyalty is ensuring satisfactory salaries, bonuses, and gratifications where and whenever this is possible. Attending to the welfare of the employees and showing concern for their wellbeing is also part of the aspects that enhance group boundedness and loyalty. In addition, the mediumterm prospects of promotion and other benefits, even the acquisition of a broader experience would make employees keep to a company and adhere to its culture and value its identity.

Larger and well-established companies offer in-house training to their employees and a significant subject taught is company identity and how it is expressed in everyday encounters and activities both with the staff and the clients (outsiders).

Do companies or smaller agencies use sanctions or punishments for the inadequate conduct or misconduct of their employees who flout the obligation to promote company or group identity? The measures taken by managers for cases of misconduct range from verbal notifications to financial or salary cuts. In 
more serious cases, when the employees fail to attend to their responsibilities and purposefully ignore the characteristics that stand for their group identity, the managers may resort to the dismissal of the guilty employees.

Very often, especially younger employees are more inclined to leave the company or the agency when they are dissatisfied on the following grounds: their incapacity to cope with company work and workload, incapacity to adapt to the group and its characteristics or rules, mistrust and lack of confidence in the management and their decisions, lack of adequate or friendly working conditions and environment, an unfriendly group identity to which the employees cannot adhere, lack of incentives and many other.

However, from the perspective of employees, the main characteristics that travel company employees can transmit to the clients in respect of group identity are: professionalism, involvement, honesty, confidence, friendliness and common sense. The degree to which professionals working in a travel agency are aware or are made aware of these characteristics and the necessity to convey the right message to the public in their professional encounters depends on the management and their capacity to enhance both the required skills and the appropriate competences. It is the management members or experts who must duly inform the employees of their group responsibilities and develop the employees' skills to work with both backstage and frontstage characteristics.

In order to ensure a smooth, efficient and reliable group identity construction local practices and the history of the company must be taken into account. Perhaps Richards' remarks that 'Nothing happens of itself; somewhere there is a history, somehow there are consequences' (2006, p. 12) should be remembered and followed. Yet, no analysis of identity construction lends itself to generalisations, so more and more insightful investigations should be carried out in order to find commonalities and differences regarding the way in which company or group identity is formed and fostered.

\section{Conclusions}

The construction of identity has been approached by many sociologists and linguists for almost three decades. The present study sought to add an empirical perspective to the research heritage. Its focus is, however, limited to the discussion of the identity construction of tourism agency employees. The background for the study was provided by a brief survey of the major contributions to the definition and development of identity studies. While surveying the advancements made in the field (Goffman, 1950; Sacks, 1960; 
Schegloff, 1987) and emphasising the interdisciplinary nature of the processes involved in the identity construction of groups, the study highlights the interdisciplinary nature of the processes and of the perspectives involved in the identity construction of groups.

In tourism the research on identity construction or reconstruction was mainly focused on tourist identities (Harrison, 2003; Thurlow \& Jaworsky, 2010) and relationships in tourism (Thurlow \& Jaworsky, 2010) and showed little interest in professional group identity. In a period in which sociological perspectives permeated practically all research areas, the present study looks at some sociolinguistic considerations that have acquired relevance in the identity formation of groups of employees in tourism. The perspective is informed by discourse and interactional sociolinguistic concepts and views.

In line with the assumption that institutional interaction reveals both the peculiarities of some given situations and the wider underlying context of norms and practices (Richards, 2006), the study pointed out the insubstantial and unsuccessful practices of managers of tourism agencies. The findings resulting from the discussions carried out with employees of some tourism agencies based in the Romanian city of Cluj-Napoca revealed that the agents were little aware of what group identity, in this particular case, agency identity really meant. Their representation of group identity was the result of their own opinions, as no one attended to their purposeful instruction in matters of agency identity, nor did anyone raise their awareness of the relevance of what group identity means and what significance or impact it may have on the agency's interaction with its customers (or outside world). The lack of involvement of those in charge (managers, group heads and employees themselves) in the process of group identity construction, reconstruction or identity survival and its control result, in most cases, in group disintegration. The study did not examine the linguistic aspects involved in the process of identity construction through social and professional interaction, instead its purpose was to lay bare some aspects that account for the misrepresentation and failure of group identity representation.

\section{REFERENCES}

1. Atkinson, P. \& Silverman, D. (1997), Kunderas Immortality: The Interview Society and the Invention of the Self, Qualitative Inquiry 3, pp 304-25.

2. Arminen, I. (2002), Design-oriented Sociology, Acta Sociologica, Vol.2, No.4, December 1, 2002, pp 315-332.

3. Bolinger, D. (1975), Aspects of Language, $2^{\text {nd }}$ ed., Harcort. 
4. Cicourel, A. (2003), On Contextualizing Applied Linguistic Research in the Workplace, Applied Linguistics, Vol. 24, No 3, Sep 2003, pp. 360-73.

5. Craib, I. (1998), Experiencing Identity, Sage.

6. Drew, P. (2003a), Comparative analysis of talk-in-interaction in different institutional settings: A sketch, in Glenn, P., LeBaron, C.D., Mandelbaum, Jenny, eds., Studies in Language and Social Interaction: In honor of Robert Hopper, Mahwah, NJ, Lawrence Erlbaum, pp. 293-308.

7. Drew, P. (2003b), Precision and exaggeration in interaction, American Sociological Review, vol. 68, pp. 917-938.

8. Drew, P. \& Heritage, J. (1993), Talk at Work: Interaction in Institutional Settings, Cambridge University Press.

9. Drew, P. \& Sorjonen, Marja-Leena (1997), Institutional dialogue, in van Dijk T.A. (ed.), Discourse Studies: A Multidisciplinary Introduction, Sage, London, pp. 92-118.

10. Garfinkel, H. (1967), Studies in Ethnomethodology, Prentice Hall.

11. Goffman, E. (1981), Forms of Talk, University of Pennsylvania Press.

12. Hannam, K, \& Knox, D. (2015), Understanding Tourism: A critical Introduction, Sage.

13. Hester, S. \& Eglin, P. (1997), Culture in Action: Studies in Membership Categorization Analysis, Studies in Ethnomethodology and Conversation Analysis, International Institute for Ethnomethodology and Conversation Analysis, University Press of America, Washington DC.

https://books.google.ro/books?hl=en\&lr=\&id=tT7FxxMnXHOC\&oi=fnd\&pg=PR4\&dq $=$ membership+categorization+analysis\&ots=TsC80B9sPD\&sig=WHP2Edvyoqihr7gy $z G A 3 k 7 E d W W U \&$ redir_esc $=y \# v=$ onepage\&q=membership $\% 20$ categorization $\% 20 a$ nalysis\&f=false, last accessed on 8 Nov. 2018.

14. Irimiea, Silvia Blanca (2018), The Relationship between the Language of Tourism, Tourism and Sociology, European Journal of Social Science Education and Research, May-August 2018, Vol. 5, Issue 2, ISSN 2411-9563, pp. 139-151.

15. Irimiea, Silvia Blanca (2019), Discourse and Society, Presa Universitară Clujeană.

16. Jaworski, A. \& Coupland, N., eds. (2014), The Discourse Reader, Routledge, London.

17. Koester, A. (2004), The Language of Work, Routledge.

18. MacLure, Maggie (1993), Arguing for Your Self: identity as an organising principle in teachers' jobs and lives, British Educational Research Journal, Vol. 19, no 4, Sept 1993, pp. 311-322.

19. Miller, Margaret A. (1994), Pressures to measure faculty work, New Directions for Institutional Research, Volume 1994, Issue 83, pp 5-14.

20. Richards, K. (2006), Language and Professional Identity: Aspects of Collaborative Interaction, Palgrave Macmillan.

21. Sacks, H. (1963), Sociological Description, Berkeley Journal of Sociology, 8, 1963, pp 1-16.

22. Sacks, H. (1967), The Search for Help. No One to Turn to, in E.S. Schneidman (ed) Essays in Self Destruction, Science House, New York, pp. 203-223.

23. Sacks, H. (1974), An analysis of the course of a joke's telling in conversation, in Sherzer, J. \& Bauman, R. (eds.), Explorations in the Ethnography of Speaking, Cambridge University Press, London, pp. 337-53. 
24. Sacks, H. (1992), Lectures on Conversation, Volumes I and II, Edited by G. Jefferson with Introduction by E.A. Schegloff, Blackwell, Oxford.

25. Sacks, H., Schegloff, E.A., Jefferson, G. (1974), A simplest systematics for the organization of turn-taking for conversation, Language, vol. 50, no. 4, pp. 696-735.

26. Schegloff, E.A. (1987), Some Sources of Misunderstanding in Talk-in-Interaction, Linguistics, vol. 25, no. 1, pp. 201-218.

27. Thurlow, C. \& Jaworsky, A. (2010), Tourism Discourse, Palgrave MacMillan.

28. Zimmerman, D.H. (1998), 0Identity, context and interaction, in Antaki, C. \& Widdicombe, Sue (eds.) Identities in Talk, Sage, London. 